\title{
High Voltage Control for lonized Chamber
}

\author{
Pritesh Kumar Jain \\ Department of Electronics Engg \\ IET DAVV, Indore, MP \\ India
}

\author{
Sanjiv Kane \\ ISUD RRCAT \\ Indore, MP \\ India
}

\author{
Chanderkant Garg \\ ISUD RRCAT \\ Indore, MP \\ India
}

\begin{abstract}
In this paper, presenting the approach to remotely control and monitor "High Voltage Module" through Personal Computer. A programmable voltage input is provided to the analog module ranging from 0 to $+4.64 \mathrm{~V}$ equals to 0 to $100 \%$ of rated voltage output $(4 \mathrm{Kv})$. Current programmability allows the user to set current limit, anywhere from 0 to $100 \%$ of maximum rated current $(5 \mathrm{~mA})$. The buffered low impedance voltage and current monitor signals can drive external circuitry directly. The $\mathrm{I}_{\mathrm{MON}}$ and $\mathrm{V}_{\mathrm{MON}}$ signal is a true output current and voltage monitoring signal. High Voltage (H.V) power supplies are used in various applications in industry. The need was to control the parameter such as voltage and current of the unit remotely and monitor the same. ADuC841 an embedded microcontroller with 8052 core of analog device is used for this application which is providing precision analog input and readout of the output voltages of high voltage module.
\end{abstract}

$\begin{array}{ll}\text { Keywords } & \\ \mathrm{HV} & \text { High Voltage } \\ \mathrm{V}_{\text {PROG }} & \text { Programmable Voltage } \\ \mathrm{I}_{\text {PROG }} & \text { Programmable Current } \\ \mathrm{V}_{\text {MON }} & \text { Voltage Monitor } \\ \mathrm{I}_{\text {MON }} & \text { Current Monitor } \\ \text { ADuC841 } & \text { Analog Device Microcontroller } \\ \text { ADC } & \text { Analog to Digital Conversion } \\ \text { DAC } & \text { Digital to Analog Conversion } \\ \text { LCD } & \text { Liquid Crystal Display } \\ \text { PWM } & \text { Pulse Width Modulation }\end{array}$

\section{INTRODUCTION}

A low noise, low ripple high voltage supply is an essential requirement for any nuclear detector. In some of the applications the detector electronics are kept in close proximity with detector. in such cases the automation provides safety, security, less cost, enhance the life of system and most important thing is provide easiness of work.

The main motive of this project was to design and develop microcontroller based card that will remotely control and monitor the high voltage analog module [1] precisely. This application will be useful to control high voltage supply for any nuclear detector which is mounted in the beam line in INDUS -2 at RRCAT Indore [2]. Most detectors used with nuclear instrumentation systems require a high voltage supply for operation .nuclear detector needs high voltage supply which should have minimum noise. Beam line area is highly restricted because of hazardous radiation, so through this application $\mathrm{i}$ can provide remote interfacing for the high voltage supply that can be controlled by personal computer.

\section{MICROCONTROLLER}

ADuC841 microcontroller [5][10] is the brain of this circuit it has large program memory space, with $62 \mathrm{kBytes}$ of flash/EE program memory, 8051 based architecture, inbuilt DAC,ADC and it suits on the industry application. Normal 8051 based architecture have 40 pin but this microcontroller provides additional functionality with $52 \mathrm{Pin}$. it also provide 12 bit 8 channel ADC and dual 12 bit DAC .It is fully compatible with 8052 Core and also use $11.0958 \mathrm{MHz}$ crystal frequency for the operation. It has additional Timer register (Timer3) which is used set the more accurate baud rate this microcontroller has in circuit serial downloading so there is no need to remove microcontroller for downloading program in the circuit.

\section{SYSTEM MODEL}

\subsection{High Voltage Module}

Spellman High Voltage Module converters use zero voltage switching power conversion topology providing exceptional efficiency and inherent low noise and ripple. The high voltage output is generated using a ferrite core high voltage step up transformer which feeds the output circuitry. Due to the fixed, high frequency conversion rate the output capacitance is small, resulting in minimal stored energy. Through the use of generously rated surge limiting resistors and a fast acting current loop, all units are fully arc and short circuit protected.

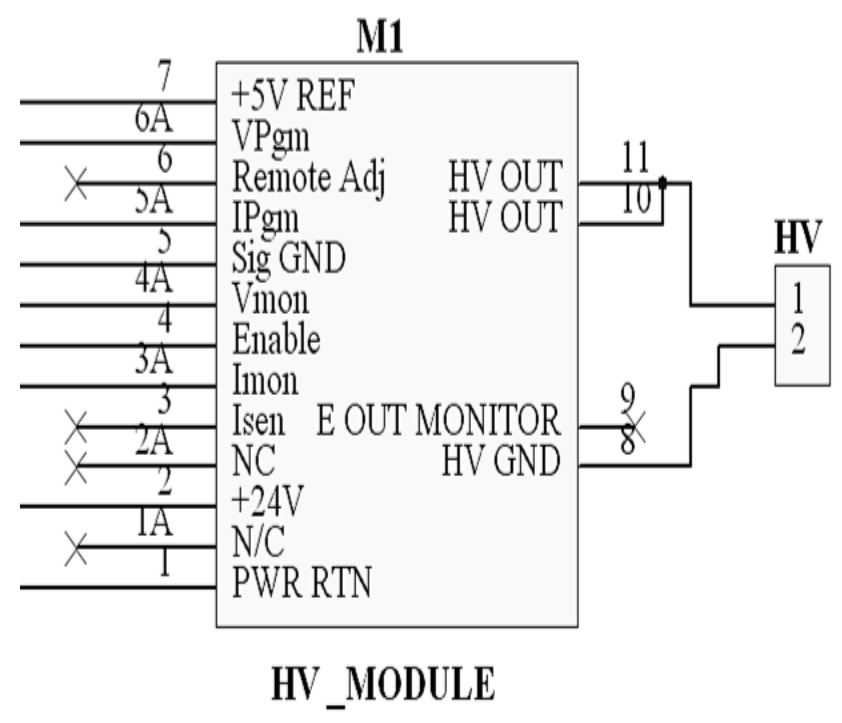

Fig.1 High voltage module

A voltage programming input is provided where 0 to $+4.64 \mathrm{Vdc}$ equals 0 to $100 \%$ of rated voltage $(4 \mathrm{Kv})$.Current programmability allows the user to set where the unit will 
current limit, anywhere from 0 to $100 \%$ of maximum rated current $(5 \mathrm{~mA})$.

This standard interface is made available via a row of 13 pins.

- $\quad$ Fixed negative or positive polarity

- Voltage and current monitor signals

- Fully arc and short circuit protected

- $\quad$ Precision $+5 \mathrm{v}$ reference output

- Comprehensive standard interface

\subsection{Circuit Description}

In order to provide programmable voltage $\mathrm{V}_{\mathrm{PROG}}$ and programmable current $\mathrm{I}_{\mathrm{PROG}}$ to the high voltage module values enter from hyper terminal or graphical software. This value is passes to the microcontroller through serial port [7], as soon as microcontroller's special function register (DACCON) is configure, microcontroller provide DAC [8] [11] output at pin 9 (D0) and pin 10 (D1) of microcontroller. Circuit description of project is shown in figure 2 .

High voltage module has a provision is that it can accept programmed [8] voltage keeping the current constant or current can programmed keeping the voltage constant. DAC output $\mathrm{V}_{\mathrm{PROG}}$ and $\mathrm{I}_{\mathrm{PROG}}$ come out from D0 and D1. Microcontroller ADuC841 configured the DAC output range from 0 volt to $\mathrm{V}_{\mathrm{REF}} 2.5$ volt. For this reason need to increase the value of DAC .After that these values from D0 and D1 passes to the OPAMP(Rail to Rail )IC U5A pin 3 and 5 in non-inverting mode and $\mathrm{V}_{\mathrm{PROG}}$ comes out at pin 1 and $\mathrm{I}_{\mathrm{PROG}}$ comes out at pin number 7 of the U5A.This U5A IC works as the voltage Doubler. Protecting high voltage module from the excess damage voltage, zener diode DZ2 and DZ3( 4.6 volt) used with zener resistance Rz1 and Rz2. This will not allow exceeding voltage range from 4.6 volt at the input of high voltage module.

$\mathrm{V}_{\mathrm{PROG}}$ and $\mathrm{I}_{\mathrm{PROG}}$ reaches to the high voltage module (M1) pin 6 A \& 5A. High voltage module works on 24 volt supply and gives high voltage output at pin $11 \& 10$.Now detector can connect to the out pin of high voltage module. High voltage module M1 provides true output monitor feedback through $\mathrm{V}_{\mathrm{MON}}$ and $\mathrm{I}_{\mathrm{MON}}$ at the pin $4 \mathrm{~A} \& 3 \mathrm{~A}$. The actual output voltage is sampled via a high impedance divider to create a voltage feedback signal (Vmon). A current feedback signal is created via a current sense resistor in the low end return of the High Voltage Output Circuitry (Imon).These two accurate ground referenced feedback signals are used to providing external monitoring If the feedback current is greater than input programmable current, then by using U7C comparator we can disable the high voltage module at pin 4

When signal transfer form circuit with high impedance to circuit with low input impedance then buffer is required for impedance matching.U4A and U7D buffer gives the solution of this impedance mismatching at output pin 1 and 14 .

Microcontroller is configured to read analog voltage range from 0 volt to the $\mathrm{V}_{\mathrm{REF}} 2.5$ volt but $\mathrm{V}_{\mathrm{MON}}$ and $\mathrm{I}_{\mathrm{MON}}$ monitor can give feedback value up to 4 volt so need to half that value. This value can be half by using the OPAMP 4342(Rail to Rail) U6B and U6D signal is provided at the pin 6 and pin 13 in inverting mode of OPAMP. This gives the negative half value of $\mathrm{V}_{\mathrm{MON}}$ and $\mathrm{I}_{\mathrm{MON}}$ voltage at pin $7 \& 14$.

To convert this negative voltage to positive value passes to the U6A and U6C at pin 2 and 9 and gives positive value at the pin $1 \&$ 8.This value passes to the RC filter U3A and U3B, then output of this filter read by the analog channel ADC0 and $\mathrm{ADC} 1$ of pin $1 \& 2$ of microcontroller. After that microcontroller pass this value to the LCD Display and Graphical software [12]-[14].

\subsection{Voltage Scaling (Double)}

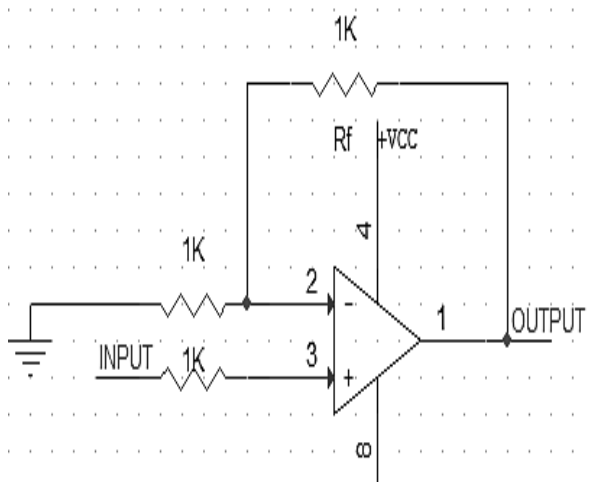

Fig. 3 Operational amplifier is in non-inverting mode.

$$
\begin{aligned}
& \mathrm{V}_{\mathrm{O}}=\left(1+\frac{\text { Feedback Resistant }}{\text { Forward Resistant }}\right) \mathrm{V}_{\mathrm{IN}} \\
& \text { Feedback resistance }=\text { forward resistance } \\
& \qquad \mathrm{V}_{\mathrm{O}}=(1+1) \mathrm{V}_{\mathrm{IN}} \\
& \mathrm{V}_{\mathrm{O}}=2 \mathrm{~V}_{\mathrm{IN}}
\end{aligned}
$$

\subsection{Voltage Scaling (Half)}

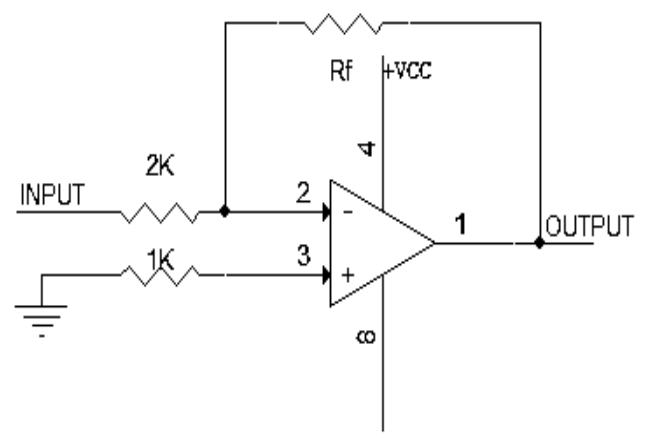

Fig. 4 Operational amplifier is in inverting mode.

$$
\mathrm{V}_{\mathrm{O}}=-\left(\frac{\text { FeedbackResistant }}{\text { TwicetheForwardResistant }}\right) \mathrm{V}_{\mathrm{IN}}
$$$$
\mathrm{V}_{\mathrm{O}}=-\mathrm{V}_{\mathrm{IN}} / 2
$$

\subsection{Buffer}

Some circuits have output impedance very high (High Voltage module). If these circuits are coupled with another circuit of low input impedance (microcontroller ADuC841), the desired functionality of the later circuit will be drastically affected, because the first circuit tries to deliver large voltage to the second and the second invariably requires small input voltage. To avoid the circuit dis functionality, a buffer circuit(a circuit with high input/output impedance and low o/p impedance) is used. 


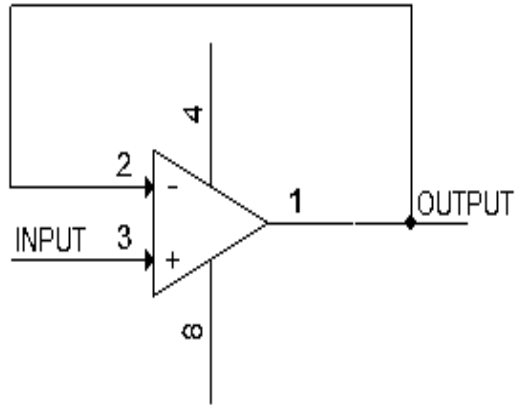

Fig. 5 Operational amplifier is as a buffer.

\section{PROBLEM FACED}

This project needs three types of supply $(+24$ volt, \pm 12 volt, 5 volt isolation), for operating the component, so the compactness of this system reduced this problem is removed by using the DC to DC Converter. This DC to DC converter takes 24 volt input and provides \pm 12 volt output. 24 volt is required for high voltage module and 12 volt is required for the OPAMP.

For the testing purpose designed a prototype PCB. At the time of grounding the top layer for reducing the noise the area near HV module also considered in the same plane. Grounding near the HV pins started arching above $1.5 \mathrm{kV}$ as the spacing was nearby. The ground plane was removed but still the problem persisted for above $2 \mathrm{kV}$. In the new PCB design care was taken by not placing the ground plane nearby HV module and sufficient spacing between the module and other components. Power lines were routed on the bottom layer whereas rest of tracks was routed on the top layer.

\section{EXTERNAL PRECAUTION}

High voltage module has provision to off the module by enabling pin low of module. If the feedback current $\left(\mathrm{I}_{\mathrm{MON}}\right)$ is greater than input programmable current $\left(\mathrm{I}_{\mathrm{PROG}}\right)$, then by using comparator circuit it be can disable.

Optocoupler provides isolation to protect the PC from high voltage. Optocoupler provides isolation between two voltage levels.

\section{ACKNOWLEDGMENTS}

The authors would like to thank Raja Ramanna Centre for advanced Technology (RRCAT), Indore for providing necessary laboratory facilities. Technical assistance from IETDAVV, Indore is highly acknowledged.

\section{REFERENCES}

[1] Um Series Manual/Spellman High Voltage Electronics/118097-001 Rev / www.spellmanhv.com / manuals/ UM/ high voltage module.

[2] http://www.cat.gov.in/technology/accel/indus/index.html /Raja Ramanna Center for Advanced Technology Indore.

[3] PROTEL99SE/printed circuit board design with PROTEL SE99/printed by star printery pty Ltd.

[4] PCB Design Flow Chart /http:// www.engineersgarage.com/ articles/ printed circuit boards pcb design manufacturing? page $=7$.

[5] Jivan S. Parab, Vinod G. Shelake, Rajanish K. Kamat, Gourish M. Naik /Exploring C For Microcontrollers/Published by Springer/2007.

[6] Embedded system / http:// www.engineersgarage.com/ articles/ embedded-systems.

[7] Serial Communications RS232/ RS422/ RS485 / www.omega.com/ techref / das/ rs-232 422-485

[8] Embedded c programming language http:// www.engineersgarage.com/ tutorials/ emebedded-clanguage

[9] Pulse width modulation http://en.wikipedia.org/wiki/ Pulse-width_modulation.

[10] Muhammad Ali Mazidi , Janice Gillispie Mazadi , Rolin D Mckinlay / The 8051 Microcontroller And Embedded Systems (Using Assembly And C)/Dorling Kindersley (India) / Second Edition Fourth Impression /2009).

[11] Datasheet /Analog device/ ADuC841/ ADuC842/ ADuC843 /Micro Converter ${ }^{\circledR}$ Multichannel 24-/16-Bit ADCs with Embedded $62 \mathrm{kB}$ Flash and Single-Cycle $\mathrm{MCU} / 2003)$.

[12] Keil Software - C $x 51$ Compiler User's Guide 09.2001/ Optimizing C Compiler and Library Reference for Classic and Extended 8051 Microcontrollers.

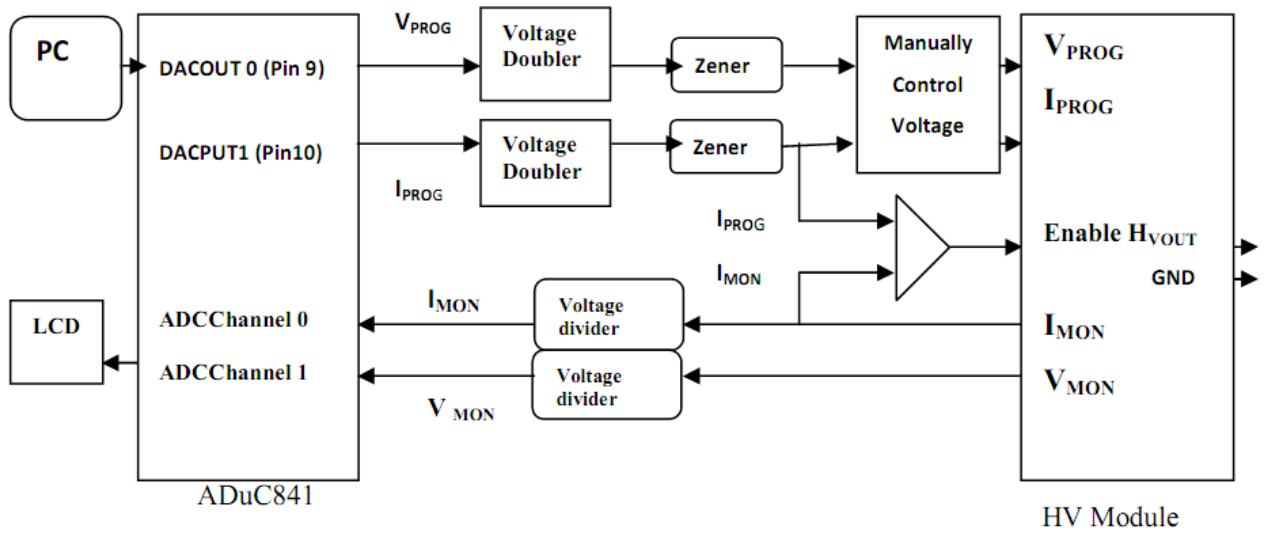

Fig.2 Circuit description 